\title{
Cellular localization of D-lactate dehydrogenase and NADH oxidase from Archaeoglobus fulgidus
}

\author{
VISHWAJEETH REDDY PAGALA, ${ }^{1}$ JOOHYE PARK, ${ }^{1}$ DAVID W. REED ${ }^{1,2}$ and PATRICIA L. \\ HARTZELL ${ }^{3,4}$ \\ ${ }^{1}$ Department of Microbiology, Molecular Biology, and Biochemistry, University of Idaho, Moscow, ID 83844-3052, USA \\ 2 Present address: Idaho National Engineering and Environmental Laboratories, Idaho Falls, ID 83415, USA \\ 3142 Life Science, University of Idaho, Moscow, ID 83844-3052, USA \\ ${ }^{4}$ Author to whom correspondence should be addressed (hartzell@ uidaho.edu)
}

Received October 10, 2001; accepted February 5, 2002; published online March 6, 2002

\begin{abstract}
Summary Members of the genus Archaeoglobus are hyperthermophilic sulfate reducers with an optimal growth temperature of $83^{\circ} \mathrm{C}$. Archaeoglobus fulgidus can utilize simple compounds including D-lactate, L-lactate and pyruvate as the sole substrate for carbon and electrons for dissimilatory sulfate reduction. Previously we showed that this organism makes a D-lactate dehydrogenase (Dld) that requires FAD and $\mathrm{Zn}^{2+}$ for activity. To determine the cellular location and topology of Dld and to identify proteins that interact with Dld, an antibody directed against Dld was prepared. Immunocytochemical studies using gold particle-coated secondary antibodies show that more than $85 \%$ of Dld is associated with the membrane. A truncated form of Dld was detected in immunoblots of whole cells treated with protease, showing that Dld is an integral membrane protein and that a significant portion of Dld, including part of the FAD-binding pocket, is outside the membrane facing the S-layer. The gene encoding Dld is part of an operon that includes noxA2, which encodes one of several NADH oxidases in A. fulgidus. Previous studies have shown that NoxA2 remains bound to Dld during purification. Thin sections of A. fulgidus probed simultaneously with antibodies against Dld and NoxA2 show that both proteins co-localized to the same sites in the membrane. Although these data show a tight interaction between NoxA2 and Dld, the role of NoxA2 in electron transport reactions is unknown. Rather, NoxA2 may protect proteins involved in electron transfer by reducing $\mathrm{O}_{2}$ to $\mathrm{H}_{2} \mathrm{O}_{2}$ or $\mathrm{H}_{2} \mathrm{O}$.
\end{abstract}

Keywords: co-localization, dissimilatory sulfate reduction, electron transfer, immunocytochemistry, oxidative stress, S-layer.

\section{Introduction}

The domain Archaea contains two genera, thermophilic Archaeoglobus and thermoacidophilic Caldivirga, which obtain energy by reducing sulfate to $\mathrm{H}_{2} \mathrm{~S}$ under anaerobic conditions. Archaeoglobus spp. have been isolated from extreme environ- ments, such as ocean and terrestrial oil deposits, where they likely account for the formation of $\mathrm{H}_{2} \mathrm{~S}$-contaminated "sour oil." Both Archaeoglobus fulgidus and Caldivirga maquilingensis thrive at $85^{\circ} \mathrm{C}$, their optimal growth temperature (Stetter 1988, Itoh et al. 1999).

The enzymes involved in sulfate reduction, ATP sulfurylase, adenylsulfate reductase and sulfite reductase, have been characterized in A. fulgidus (Speich et al. 1988, Dahl et al. 1990) and are similar to enzymes involved in sulfate reduction in mesophilic bacteria (Hansen 1994). During dissimilatory sulfate reduction, sulfate is activated by ATP to form adenosylphosphosulfate (APS) (Hansen 1988). This reaction is catalyzed by ATP sulfurylase. Adenosylphosphosulfate is then reduced to bisulfite in a $2 e^{-}$transfer reaction by adenylsulfate reductase. Sulfite reductase catalyzes the final conversion of bisulfite to hydrogen sulfide.

During dissimilatory sulfate reduction, electrons can be obtained from substrates such as lactate or pyruvate. Archaeoglobus fulgidus can use either D- or L-lactate as its sole source of carbon and energy (Stetter 1988). Archaeoglobus fulgidus produces two membrane-associated proteins, D-lactate dehydrogenase (Dld) and L-lactate dehydrogenase, to oxidize Dand L-lactate, respectively, and transfer electrons to the anaerobic respiratory chain (Reed and Hartzell 1999). Although the initial steps in lactate utilization are poorly understood, electrons are probably transferred through intermediate carriers, such as cytochromes and quinones in the membrane. The D-lactate dehydrogenase shares identity with the cytochromedependent D-lactate dehydrogenases that are used during anaerobic respiration to generate a proton motive force for growth. Archaeoglobus fulgidus has a single $c$-type cytochrome, which is a potential acceptor of electrons from Dld in vivo (D.W. Reed, V.R. Pagala and P.L. Hartzell, unpublished data).

D-Lactate dehydrogenase is transcribed from a gene that is part of an operon including noxA2, which encodes a protein related to water-forming NADH oxidases from Borrelia burgdorferi (35\% identity, 56\% similarity), Enterococcus faecalis 
(33\% identity, 53\% similarity) (Ahmed and Claiborne 1989, Ross and Claiborne 1992) and Pyrococcus abysii (56\% identity, 71\% similarity) (BLAST analysis, Altschul et al. 1990). Some Nox enzymes can carry out a $2 e^{-}$transfer to $\mathrm{O}_{2}$ to yield $\mathrm{H}_{2} \mathrm{O}_{2}$, whereas others can carry out a $4 e^{-}$transfer to yield $\mathrm{H}_{2} \mathrm{O}$. A subset of Nox enzymes can carry out both reactions (Ward et al. 2001). Nox enzymes that can reduce $\mathrm{O}_{2}$ to $\mathrm{H}_{2} \mathrm{O}$ carry a critical cysteine residue near the $\mathrm{N}$-terminus $(\mathrm{C} 42)$ that is essential for the $4 e^{-}$reduction of $\mathrm{O}_{2}$ to $\mathrm{H}_{2} \mathrm{O}$ (Mallett and Claiborne 1998). In addition to its ability to transfer electrons to $\mathrm{O}_{2}$, A. fulgidus NoxA2 has diaphorase activity because it can transfer electrons to other acceptors, such as cytochrome.

The NADH oxidases comprise a diverse group of enzymes that can be either soluble (Gomes and Teixeira 1998), membrane associated (Ne' eman and Razin 1975), or integral membrane proteins (Berridge and Tan 2000a, 2000b). In anaerobes, Nox enzymes are thought to protect sensitive enzymes from $\mathrm{O}_{2}$ by converting $\mathrm{O}_{2}$ to $\mathrm{H}_{2} \mathrm{O}$ (Brown et al. 1998). In aerobes, Nox enzymes are thought to play a critical role in regenerating $\mathrm{NAD}^{+}$, but have also been shown to interact with peroxiredoxin, a disulfide-containing redox protein, to remove $\mathrm{H}_{2} \mathrm{O}_{2}$ (Nishiyama et al. 2001). In facultative anaerobes that lack a respiratory chain, NADH oxidase activity is typically increased substantially in cells grown aerobically compared with cells grown anaerobically (Nishiyama et al. 2001).

The enzyme NoxA2 is one of at least eight NADH oxidases that are present in A. fulgidus. Although A. fulgidus does not appear to produce superoxide dismutase, a superoxide scavenger neelaredoxin (Nlr) (Abreu et al. 2000, 2001) can remove the superoxide radical $\mathrm{O}_{2}{ }^{--}$. Neelaredoxin can reduce $\mathrm{O}_{2}{ }^{-{ }^{-}}$directly to $\mathrm{H}_{2} \mathrm{O}_{2}$, in which case regeneration of reduced Nlr requires an NADH oxidase.

Previously, we have shown that NoxA2 is associated with Dld during purification from A. fulgidus extracts. To better understand the components involved in electron transport and the relationship between Dld and NoxA2, the topology and cellular locations of these enzymes were examined. Here we report that Dld is an integral membrane protein that associates with NoxA2, which is located between the membrane and the S-layer (i.e., in the s-periplasm).

\section{Materials and methods}

\section{Growth of Archaeoglobus fulgidus}

Archaeoglobus fulgidus VC-16 (DSM4304) was obtained from Karl Stetter (Lehrstuhl für Mikrobiologie, Universität Regensburg) (Stetter 1988, 1992). The cells were grown at $83{ }^{\circ} \mathrm{C}$ in anaerobic sulfate-thiosulfate-lactate (STL) medium gassed with $\mathrm{N}_{2}$ (Reed and Hartzell 1999). Archaeoglobus fulgidus was also grown with pyruvate $(22 \mathrm{mM})$ as the electron donor. Sulfate-thiosulfate-lactate medium was modified from Balch medium 3 (Balch et al. 1979) as follows: 20 mM PIPES (piperazine- $N, N^{\prime}$-bis(2-ethanesulfonic acid)) buffer was substituted for $\mathrm{NaHCO}_{3} ; 11.2 \mathrm{mM}$ sodium lactate was substituted for sodium acetate; $0.5 \mathrm{~g}$ of yeast extract $\mathrm{l}^{-1}$ was substituted for trypticase and trace vitamin solution; and $0.11 \mathrm{mg}$ of
$\mathrm{NiSO}_{4} \cdot 6 \mathrm{H}_{2} \mathrm{O}^{-1}$ was added. The medium was reduced with $1 \mathrm{mM} \mathrm{Na}_{2} \mathrm{~S}$ and $1 \mathrm{mM} \mathrm{Na}_{2} \mathrm{~S}_{2} \mathrm{O}_{3}$ and then inoculated with $5 \%$ (v/v) of logarithmic-phase A. fulgidus cells. Where applicable, cells were harvested by centrifugation at $16,000 \mathrm{~g}$ for $15 \mathrm{~min}$ at $4{ }^{\circ} \mathrm{C}$, then lysed by passage through a French pressure cell at 137.9 MPa and centrifuged at 230,000 $\mathrm{g}$ for $1 \mathrm{~h}$ at $4{ }^{\circ} \mathrm{C}$ in a Sorvall S100AT5 rotor (Dupont, Newton, CT). The pellet and supernatant were subsequently assayed. Chemicals used in making media and performing assays were obtained from Sigma (St. Louis, MO).

\section{Preparation and use of antibodies}

D-Lactate dehydrogenase was purified as described earlier (Reed and Hartzell 1999) and used to immunize a chicken. Anti-Dld polyclonal antibodies were purified from egg yolk using the Eggcellent Ig-Y purification kit from Pierce (Rockford, IL). Anti-NoxA2 polyclonal antibodies were raised in rabbits and obtained from Pocono Rabbit Farms (Canadensis, PA). Aliquots of membrane and soluble fractions of $A$. fulgidus cells after ultracentrifugation were boiled in sodium dodecyl sulphate (SDS) sample buffer and then separated by $10 \%$ Tricine SDS-polyacrylamide gel electrophoresis (SDSPAGE) (Schagge and von Jagow 1987). The proteins were then transferred onto polyvinylidene difluoride (PVDF) nylon membrane (Immobilon $\mathrm{P}^{\mathrm{SQ}}$, Millipore, Bedford, MA) using a mini trans-blot cell (Bio-Rad, Hercules, CA) and blocked overnight in 5\% milk. Primary and secondary antibodies were used at 1:5000 dilution. The secondary antibody was conjugated with horseradish peroxidase and assayed with the electrochemiluminescence (ECL) detection kit (Amersham-Pharmacia, Piscataway, NJ).

\section{Sample preparation for electron microscopy}

Archaeoglobus fulgidus cells grown to logarithmic phase were fixed with $1.25 \%$ glutaraldehyde and $2 \%$ paraformaldehyde in $50 \mathrm{mM}$ PIPES buffer at $\mathrm{pH} 7$ overnight at $4{ }^{\circ} \mathrm{C}$. The cells were rinsed, resuspended in $50 \mathrm{mM}$ PIPES buffer and dehydrated by incubating the sample in increasing concentrations of ethanol from 30 to $100 \%$. The cells were then infiltrated with the epoxy resin LR white (London Resin white; Polysciences, Warrington, PA). The infiltration was performed over 3 days with three changes of $100 \%$ LR white. The cells were then transferred to fresh resin and cured in the oven at $65{ }^{\circ} \mathrm{C}$ for 2 days in $0.5 \mathrm{ml}$ Eppendorf tubes. The resin-embedded samples were used to make ultra-thin sections of 50-200 nm with a microtome (Reichert, Germany).

Sections were collected onto Nickel-200 mesh grids coated with $0.25 \%$ formvar in chloroform before immunolabeling. The grids were placed on microtiter plates and blocked with Tris-buffered saline with Tween (TBST) buffer $(175 \mathrm{mM} \mathrm{NaCl}$ and $0.3 \%$ Tween-20) for $2.5 \mathrm{~min}$ in the microwave (Pelco, Redding, CA) at $37{ }^{\circ} \mathrm{C}$ and for another $2.5 \mathrm{~min}$ at room temperature (Berryman and Rodewald 1990). The grids were then rinsed twice with TBST, and incubated with a 1:25 dilution of anti-Dld primary antibody for $2.5 \mathrm{~min}$ in the microwave at 37 ${ }^{\circ} \mathrm{C}$ and another $2.5 \mathrm{~min}$ at room temperature. Grids were rinsed 
twice with TBST, then incubated with a 1:100 dilution of goat anti-chicken secondary antibody conjugated with 18 -nm gold particles. The grids were rinsed once with $2.25 \mathrm{M} \mathrm{NaCl}$ for 15 $\mathrm{s}$ and twice with distilled water and dried. The control grid was prepared as described for the treatment grid, except it was not treated with the primary antibody. Dried sections were stained with a 1:3 ratio of $1 \% \mathrm{KMnO}_{4}$ and $2 \%$ uranylacetate (Terzakis 1968) for $5 \mathrm{~min}$ and then rinsed thoroughly to remove the excess stain. The grids were air-dried and then analyzed with a JEOL transmission electron microscope (Peabody, MA). The microscope was operated at an acceleration voltage of $80 \mathrm{kV}$ and the electron micrographs were taken at magnifications ranging from $20,000 \times$ to $75,000 \times$.

\section{Co-localization of Dld and NoxA2}

For co-localization (Reno 2001), LR white sections and grids were prepared as described earlier in Materials and methods. Immuno-labeling was performed similar to Dld localization with the exception that antibodies for Dld and NoxA2 were applied simultaneously. Primary antibodies for Dld and NoxA2 were used at 1:25 and 1:10 dilutions, respectively. Secondary antibodies for both proteins were used at a dilution of 1:100. Secondary antibody used for Dld gold labeling was rabbit anti-chicken antibody conjugated with 18-nm gold particles (Jackson Immuno-Research Laboratories, West Grove, PA). Secondary antibody used for NoxA2 gold labeling was goat anti-rabbit antibody conjugated to $10-\mathrm{nm}$ gold particles (BBI International, Cotopaxi, CO).

\section{Spheroplast preparation}

Archaeoglobus fulgidus cells grown to logarithmic phase were harvested by centrifugation at $10,000 \mathrm{~g}$ for $15 \mathrm{~min}$ at $4{ }^{\circ} \mathrm{C}$. The cells were suspended in 2-( $N$-morpholino)ethanesulfonic acid (MES) buffer with 25\% sucrose. Proteinase K (Sigma) was added to a final concentration of $250 \mu \mathrm{g} \mathrm{ml}^{-1}$ and samples were then incubated at $37{ }^{\circ} \mathrm{C}$ for $30 \mathrm{~min}$. A sample of cells without protease was treated in parallel as a control. One hundred $\mu \mathrm{l}$ aliquots were taken at intervals of 10, 20 and $30 \mathrm{~min}$ from the protease-treated samples. The control cells were centrifuged in a microfuge at $5000 \mathrm{rpm}$ for $8 \mathrm{~min}$ and the cell pellet and supernatant were separated. The various aliquots were boiled in SDS sample buffer and separated by $10 \%$ Tricine SDS-PAGE. The proteins were then blotted onto PVDF nylon membrane (Immobilon $\mathrm{P}^{\mathrm{SQ}}$ ) and blocked overnight in $5 \%$ milk, then probed with antibodies as previously described.

To ensure that the integrity of the cell membrane and its contents were not compromised during protease treatment, we used chromosomal DNA, the deazaflavin $\mathrm{F}_{420}$ and triosephosphate isomerase as cytoplasmic markers. If the cell membrane is intact, addition of DNase I should have no effect on the chromosomal DNA. We added DNase I $\left(10 \mathrm{mg} \mathrm{ml}^{-1}\right)$ to control and protease-treated cells, and to control and protease-treated cells that had been sonicated briefly to lyse the cells. Reactions were incubated at room temperature for $15 \mathrm{~min}$, then heated at $65^{\circ} \mathrm{C}$ for $15 \mathrm{~min}$ to inactivate the DNase I. The samples were sonicated briefly to release chromosomal
DNA and the cell debris was removed by centrifugation. The cell lysate was run on a $0.7 \%$ agarose gel and DNA was visualized after staining with ethidium bromide.

Protease-treated cells were centrifuged briefly to separate the spheroplasts from the supernatant and the absorbance at $420 \mathrm{~nm}$ of each fraction was determined with a Perkin Elmer Lambda Bio UV/VIS spectrometer. The pellet containing A. fulgidus spheroplasts was suspended in phosphate-buffered saline (PBS), then sonicated at a setting of $3(23 \mathrm{kHz}$ at $7.5 \mathrm{~W}$; Microson Ultrasonic Cell Disruptor, Heat Systems, Farmingdale, NY) for 30 s to lyse the spheroplasts. Cell debris was removed by brief centrifugation and the absorbance of the cytoplasmic contents was determined at $420 \mathrm{~nm}$.

The activity of triosephosphate isomerase was measured spectrophotometrically by coupling the conversion of glyceraldehyde-3-phosphate to dihydroxyacetone phosphate by triosephosphate isomerase with NADH-dependent conversion of dihydroxyacetone to L-gycerol-3-phosphate by glycerol-3phosphate dehydrogenase. Archaeoglobus fulgidus does not produce an enzyme with glycerol-3-phosphate dehydrogenase activity. The reaction mixture contained $100 \mathrm{mM}$ Tris $\mathrm{pH}$ 8.0, $3 \mathrm{mM}$ glyceraldehyde-3-phosphate, $0.3 \mathrm{mM}$ NADH and $1.7 \mathrm{U}$ of glycerol-3-phosphate dehydrogenase. Reactions in which either the substrate (glyceraldehyde-3-phosphate) or enzyme (glycerol-3-phosphate dehydrogenase) was omitted were performed to serve as controls. A reaction mix containing only $\mathrm{NADH}$ was also monitored. Reactions were monitored as the change (decrease) in absorbance at $340 \mathrm{~nm}$ with a Perkin Elmer Lambda Bio UV/VIS spectrophotometer.

\section{NoxA2 enzyme assay}

Activity of NoxA2 from untreated and protease-treated cells was assayed at $55^{\circ} \mathrm{C}$. Protein samples were separated by SDSPAGE and the gel was incubated for $1 \mathrm{~h}$ with three changes of buffer (20 mM Tris at $\mathrm{pH} 7.5)$ to renature proteins. The gel was then incubated at $55^{\circ} \mathrm{C}$ for $30 \mathrm{~min}$ in $50 \mathrm{mM}$ sodium phosphate $\left(\mathrm{pH} 6.6\right.$ at $50{ }^{\circ} \mathrm{C}$ ) containing $10 \mu \mathrm{M}$ flavin adenine dinucleotide (FAD), $150 \mu \mathrm{M}$ nitro blue tetrazolium, $500 \mu \mathrm{M}$ 2-methyl-1,4-naphthoquinone (menadione) and $200 \mu \mathrm{M}$ NADH. Enzyme activity was marked by the formation of dark formazan bands that were visible within $30 \mathrm{~min}$.

\section{Results}

\section{Dld is expressed constitutively}

Archaeoglobus fulgidus VC-16 can grow heterotrophically with substrates such as D-lactate, L-lactate and pyruvate as its sole source of carbon and electrons, or lithotrophically using $\mathrm{H}_{2}$ as the electron donor and $\mathrm{CO}_{2}$ as the carbon source (Stetter 1988). Previously we have shown that $A$. fulgidus encodes a Dld that specifically converts D-lactate to pyruvate. The Dld is a $50 \mathrm{kDa} \mathrm{Zn}{ }^{+2}$ protein that requires FAD for activity. Flavin adenine dinucleotide is predicted to bind near the $\mathrm{N}$-terminus at the dinucleotide binding motif $\left(\mathrm{GXGX}_{2} \mathrm{GX}_{21} \mathrm{D} / \mathrm{E}\right)$ at residues 68 to 95 (Reed and Hartzell 1999). The ability of A. fulgidus to grow using only D-lactate for carbon and energy is surprising 
because the concentration of D-lactate is probably low in habitats where this organism is typically found. In many bacteria, expression of an operon is repressed in the absence of substrate whose products are involved in catabolism. The gene encoding Dld appears to be transcribed with four other genes in an operon. The first gene in the operon, AF0396, is predicted to encode a 260 amino acid protein whose N-terminus matches the ArsR, LuxR, AsnC and GerE families of regulatory proteins. Many of the regulatory proteins in this group act as repressors to block transcription in the absence of substrate. To determine if the $d l d$ operon is regulated in response to D-lactate, A. fulgidus cells grown with either D-lactate or pyruvate as the energy and carbon source were prepared and analyzed in immunoblots. The proteins were separated by SDS-PAGE, transferred onto PVDF membranes and probed with anti-Dld antibody. Anti-Dld antibody reacted with Dld in both lactate-grown and pyruvate-grown cells (Figure 1). Hence these results show that Dld is expressed in the absence of D-lactate and agree with earlier biochemical results showing that Dld activity is present in L-lactate- and pyruvate-grown cells.

\section{Dld is found primarily in the membrane}

In agreement with the results from immunoblot assays shown in Figure 1, Dld activity was detected in soluble and membrane fractions of A. fulgidus by the biochemical assay (Reed and Hartzell 1999). Although proteins involved in respiratory electron transfer reactions must be associated with the membrane, the presence of active Dld in both fractions raised questions about the arrangement and cellular location of Dld in A. fulgidus. Two scenarios might account for the distribution pattern for Dld. D-Lactate dehydrogenase might be a periplasmic protein that is tightly associated with the membrane,
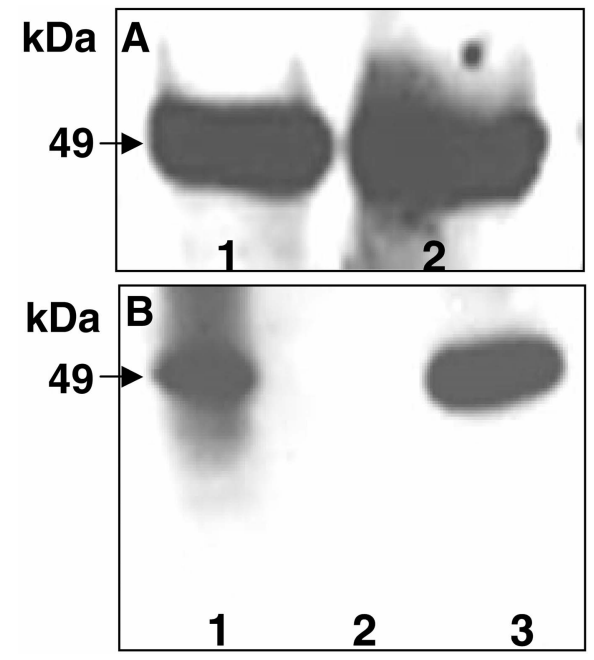

Figure 1. D-Lactate dehydrogenase is expressed constitutively. Lactate- (A) and pyruvate-grown (B) cell samples were separated on SDS-PAGE gels and probed with anti-Dld antibody. (A) Lane 1: A. fulgidus soluble fraction; Lane 2: A. fulgidus membrane fraction. (B) Lane 1: A. fulgidus soluble fraction; Lane 2: empty; Lane 3: A. fulgidus membrane fraction. (Prestained protein standards (Gibco) are not shown.) or it might be an integral membrane protein in which case the soluble form of Dld might derive from the cytosol as newly formed protein not yet inserted into the membrane. In bacteria, most proteins that are transported to the cytoplasmic membrane do not contain a signal sequence, but most secreted proteins have a signal sequence that is cleaved during transport (Broome-Smith et al. 1994). D-Lactate dehydrogenase does not have a recognizable $\mathrm{N}$-terminal signal sequence.

To begin to distinguish between these possibilities, the cellular location of Dld was analyzed by electron microscopy after immunogold labeling. Ultra-thin sections of A. fulgidus cells were incubated with anti-Dld primary antibody, followed with a secondary treatment with antibody conjugated to 18-nm gold particles. The majority of the particles were found on, or very close to, the cell membrane (Figure 2). In contrast, the control sample, which was incubated with secondary antibody only, contained very few gold particles that were distributed randomly. Gold particles inside the cell, outside the cell and in or very near the membrane were counted for individual cells in multiple thin sections to quantify the distribution of Dld. The results are summarized in Table 1. Roughly $80-85 \%$ of the gold particles were membrane-associated and very little Dld was found in the cytoplasm. Hence the soluble form of Dld that we detected may represent a mature form of Dld in the cytoplasm that is in the process of being inserted into the membrane. Alternatively, soluble Dld may result when some of the membrane-bound Dld combines with micelles that form during lysis. Typically, these micelles do not sediment with the membrane fraction during ultracentrifugation.

\section{Dld is predicted to be an integral membrane protein}

Analysis of the primary sequence of the Dld protein with transmembrane prediction programs, including DAS (Cserzo et al. 1997), TOPRED2 (von Heijne 1992), TMPRED (Hofmann and Stoffel 1993) and TMHMM (Krogh et al. 2001), showed that Dld is likely to have two membrane-spanning regions. With the exception of TMHMM, the above programs predict that regions between amino acids 183 to 200 and 383 to 403 are potential transmembrane regions. Based on the TOPRED2 program, the region from amino acids 183 to 200 of Dld scores above the threshold of 500 and is predicted to be in an outside to inside orientation. Hence, the $\sim 182 \mathrm{~N}$-terminal residues of Dld should face the S-layer, in the region (the s-periplasm) that corresponds with the periplasm of gram-negative bacteria.

The region between amino acids 384 to 402 has a score of 979 using the TOPRED2A program and is predicted to be the second transmembrane sequence, which is predicted to be in an inside to outside orientation. Hence, like the $\mathrm{N}$-terminal residues, the $60 \mathrm{C}$-terminal residues should be outside of the membrane in the periplasm. Based on these predictions, about 200 amino acids of the central core of Dld are within the membrane or fall to the inside of the membrane.

\section{Portions of the Dld protein face the S-layer}

To test the validity of the above predictions, we looked for the presence of Dld in spheroplasts of A. fulgidus cells. Archaeo- 


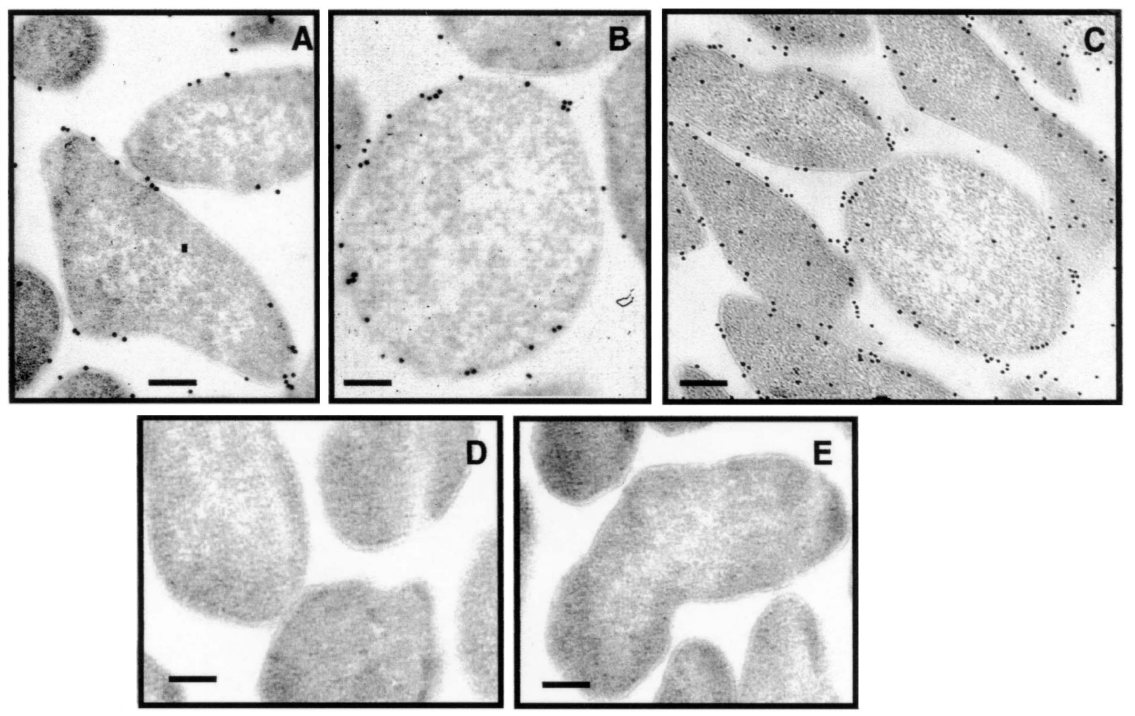

Figure 2. D-Lactate dehydrogenase is associated with the membrane. Ultrathin sections (80-200 nm) shown in A, $\mathrm{B}$ and $\mathrm{C}$ were treated with anti-Dld antibody and secondary anti-chicken antibodies conjugated with 18 -nm gold particles. Sections in D and E were incubated only with anti-chicken antibody conjugated to 18 -nm gold particles. Photographs were taken with a JEOL transmission electron microscope. Bar $=200 \mathrm{~nm}$.

globus fulgidus is surrounded by a glyco-proteinaceous Slayer in place of the peptidoglycan layer characteristic of bacteria. Although techniques involving lysozymes that are used to prepare spheroplasts in bacteria are futile, spheroplasts can be prepared by treating cells with proteases. Whole A. fulgidus cells were treated with proteinase $\mathrm{K}$, which cleaves at random sites within proteins, to remove the proteinaceous S-layer, s-periplasmic proteins and portions of membrane proteins that are exposed to the outside of the membrane. After protease treatment, the spheroplasts were separated from the digested material by centrifugation and analyzed by immunoblot. When whole cells were probed with anti-Dld antibody, a single band at about $50 \mathrm{kDa}$ was detected, which is the expected size of the native Dld protein. In contrast, when proteasetreated cells were probed with anti-Dld antibody, a single band at about $24 \mathrm{kDa}$ was detected. These results are shown in Figure 3 . The $24 \mathrm{kDa}$ product that we detected agrees with the 200 amino acid portion of Dld that is predicted from DAS, TOPRED2 and TMPRED algorithms to reside in the membrane together with the cytoplasmic domain. This suggests that the $\mathrm{N}$ - and $\mathrm{C}$-termini are susceptible to cleavage by prote-

Table 1. Distribution of gold particles in thin sections of A. fulgidus.

Cellular location Number of gold particles ${ }^{1} \quad$ Percentage of total ${ }^{2}$

\begin{tabular}{lrr}
\hline Membrane $^{3}$ & $178 / 214$ & 83 \\
Cytoplasm & $20 / 214$ & 9 \\
Extracellular & $16 / 214$ & 8 \\
\hline
\end{tabular}

1 The total number of gold particles in a section with about 5.5 A. fulgidus cells treated with both primary and secondary antibodies was 214. Sections prepared in parallel but treated only with secondary antibody had less than one particle per cell.

${ }^{2}$ The distribution of gold particles was within $\pm 5 \%$ in different thin sections that were examined.

${ }^{3}$ Gold particles that were on or very close to the membrane were considered to be associated with the membrane. ase because they are in the s-periplasm. If this model is correct, it places the FAD binding motif between residues 68 and 95, outside the cell membrane, facing the S-layer.

\section{Dld and NoxA2 may be part of a protein complex}

The second gene in the $d l d$ operon encodes an NADH oxidase, NoxA2. Although A. fulgidus encodes multiple NADH oxidases, their role in the growth of this strict anaerobe is unknown. During the purification of Dld from A. fulgidus, a protein with Nox activity remained associated with Dld. The $\mathrm{N}$-terminal sequence showed that this protein is NoxA2 (Reed et al. 2001). The close association of these two proteins suggested that they might interact or be part of a protein complex. To determine if these two proteins localize to the same area in the cell, thin sections of $A$. fulgidus were probed simultaneously with primary antibodies against Dld (chicken) and NoxA2 (rabbit) followed by secondary antibodies conjugated

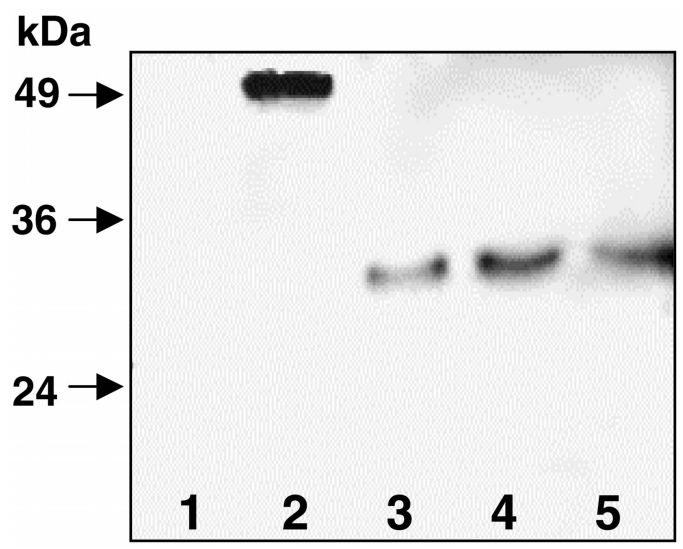

Figure 3. Portions of Dld are vulnerable to protease digestion. Whole cells were treated with proteinase $\mathrm{K}$ and the size of Dld remaining was analyzed by immunoblot. Lane 1: wash from untreated whole cells; Lane 2: untreated whole cells; Lanes 3-5: whole cells treated with proteinase $\mathrm{K}$ for 10 (Lane 3), 20 (Lane 4) and $30 \mathrm{~min}$ (Lane 5). 
to gold particles of different sizes. When particles in the double-labeled cells were quantified for Dld and NoxA2, $80 \%$ of the small particles that identify NoxA2 were clustered with the large particles that identify Dld (Figure 4). Of the cells examined, there were, on average, 25 large gold particles per cell of which 20 were less than one particle length away from one or more small gold particles.

\section{NoxA2 is predicted to be a soluble protein}

The association between NoxA2 and Dld during the purification of Dld and the clustering of Dld with NoxA2 in whole cells were compelling evidence that these proteins interact or are part of a complex. The finding that all of the particles that identify NoxA2 were membrane-associated prompted us to examine the predicted topology of NoxA2. Because the programs DAS, TMHMM 2.0, TMPRED and HMMTOP 2.0 yielded results that were consistent with our empirical data for Dld, we applied these programs to NoxA2. The algorithms HMMTOP 2.0 and TMHMM 2.0 do not predict any transmembrane helices for NoxA2. The DAS program identifies three regions of NoxA2 with hydrophobic amino acids that are considered potential transmembrane segments (residues 148153, 230-234 and 396-397), but in each case the length of the segment is too short to span a typical prokaryotic membrane. The TMPRED program also predicts NoxA2 to have three transmembrane regions (residues 1-19, 298-321 and 396424) and positions the N-terminus in the cytoplasm.

\section{NoxA2 is located between the membrane and the S-layer}

The results of these four algorithms failed to provide a coherent picture of the topology or position of NoxA2. The results of co-localization studies showed that NoxA2 is associated with the membrane, but did not reveal whether NoxA2 is asso- ciated with the cytoplasmic or the periplasmic face of the membrane. Proteins that are exported to the periplasm often have signal sequences that direct their transport (Brockman and Wood 1975, von Heijne 1988). However, programs designed to detect signal sequences failed to identify a suitable sequence at the N-terminus of the NoxA2 protein. To determine if NoxA2 resides in the cytoplasm or the s-periplasm, whole cells of $A$. fulgidus were treated with various proteases to remove the S-layer and proteins that are in the s-periplasm or that have domains facing the s-periplasm. When immunoblots of protease-treated cells were probed with anti-NoxA2 antibody, no band was detected (Figure 5). In contrast, when immunoblots of whole cells were probed with anti-NoxA2 antibody, a single band at about $50 \mathrm{kDa}$ was detected, which is the expected size for the intact NoxA2 protein. When protease-treated samples that lacked NoxA2 were probed in parallel with anti-Dld antibody, a 24-kDa band corresponding to partially digested Dld was detected. As internal controls for the protease digestion experiment, the presence of chromosomal DNA and the deazaflavin $\mathrm{F}_{420}$ was monitored. No $\mathrm{F}_{420}$ was detected in the material released with the $\mathrm{S}$-layer and periplasmic contents of the protease-treated cells $\left(\mathrm{Abs}_{420}=0.02\right)$. By comparison, when the cytoplasmic fraction of lysed spheroplasts was examined spectrophotometrically, the absorbance at $420 \mathrm{~nm}$ was 1.6. To further ensure that protease-generated spheroplasts were intact, two additional controls were performed. First, we examined whether spheroplasts were impermeable to exogenous enzyme. We added DNaseI to both intact spheroplasts and spheroplasts that had been sonicated briefly to disrupt the membrane. Chromosomal DNA from the intact spheroplasts and whole cells was resistant to degradation by DNaseI, whereas DNA from the lysed spheroplasts was degraded (Figure 6). Second, we assayed the activity of triose-

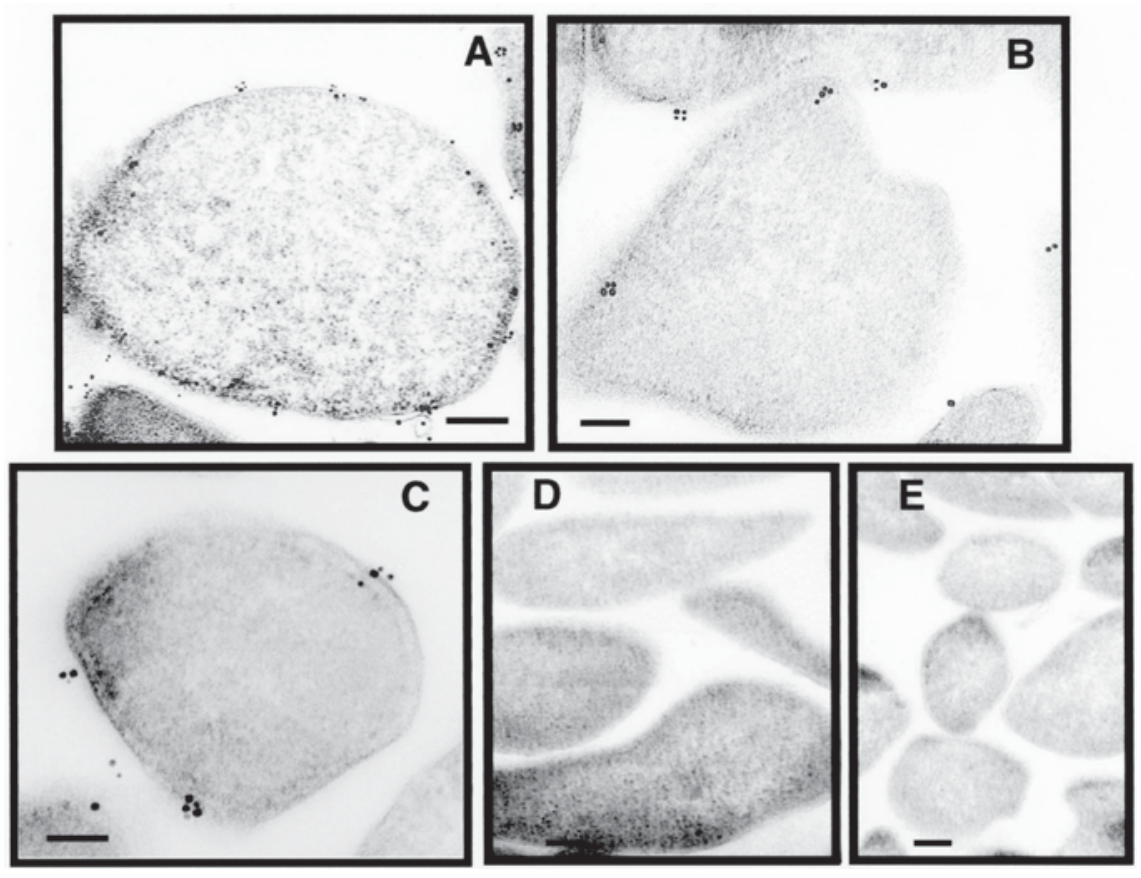

Figure 4. The Dld and NoxA2 co-localize in the membrane. Ultra-thin sections $(80-200 \mathrm{~nm})$ in $\mathrm{A}, \mathrm{B}$ and $\mathrm{C}$ were treated with anti-Dld (from chicken) and anti-NoxA2 (from rabbit) followed by anti-rabbit antibody conjugated with 10-nm gold particles and anti-chicken antibody conjugated with 18-nm gold particles. Thin sections in Panels D and E were treated only with secondary antibodies. Photographs were taken under a JEOL transmission electron microscope. $\mathrm{Bar}=50 \mathrm{~nm}$. 


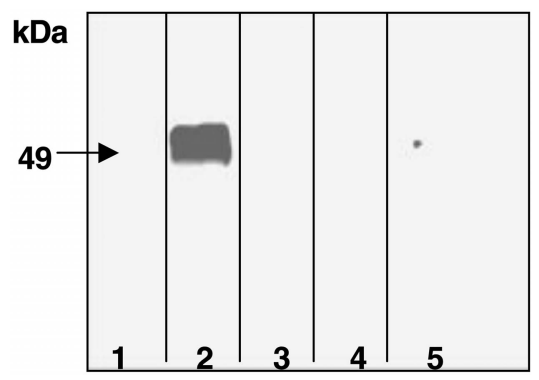

Figure 5. Proteinase K digestion for NoxA2 topology. Whole cells were treated with proteinase $\mathrm{K}$ and the NoxA2 remaining was analyzed by immunoblot. Lane 1: wash from untreated whole cells; Lane 2: untreated whole cells; Lanes 3-5: whole cells treated with proteinase $\mathrm{K}$ for 10 (Lane 3), 20 (Lane 4) and $30 \mathrm{~min}$ (Lane 5).

phosphate isomerase, an enzyme that is predicted to reside in the cytoplasm. When the reaction mixtures with the protease-treated cells and whole cells were analyzed at $340 \mathrm{~nm}$ for NADH absorption, the absorbance decreased over time, indicating the oxidation of NADH (Figure 7). The control reactions showed no significant change in absorption at $340 \mathrm{~nm}$.

These data indicate that only the S-layer, s-periplasmic proteins and segments of proteins exposed to the s-periplasm are sensitive to protease treatment. Considering the results from immunocytochemical localization, protease sensitivity and biochemical fractionation assays, it can be inferred that NoxA2 is loosely associated with the membrane on the periplasmic side. A model of the topology of NoxA2 is depicted in Figure 8.

The finding that NoxA2 is located between the membrane and the S-layer was surprising, but consistent with the fact that it associates with the integral membrane protein Dld. To determine if the location of NoxA2 is unique to this enzyme or characteristic of other NADH oxidases in A. fulgidus, we compared the activity profiles of NADH oxidases in intact

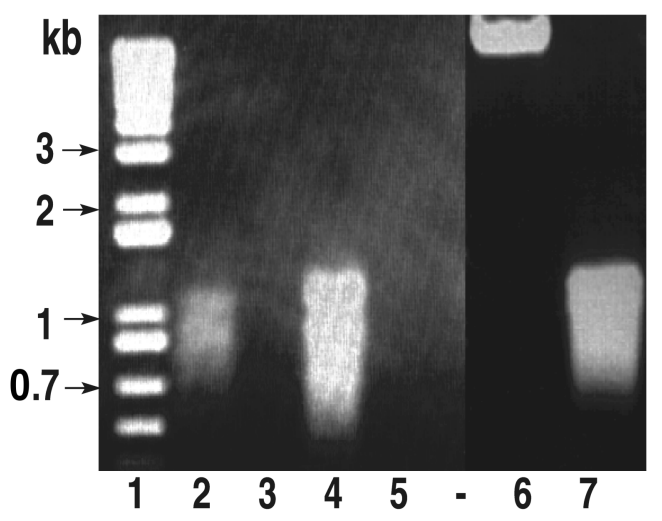

Figure 6. Protease-treated cells are resistant to DNaseI. Lane 1: $1 \mathrm{~kb}$ DNA ladder standards; Lane 2: DNA from protease-treated cells, sonicated, then incubated with DNaseI; Lane 3: empty; Lane 4: DNA from protease-treated cells incubated with DNaseI; Lane 5: empty; Lane 6: chromosomal DNA isolated from fresh A. fulgidus cells; Lane 7: DNA from untreated whole cells.

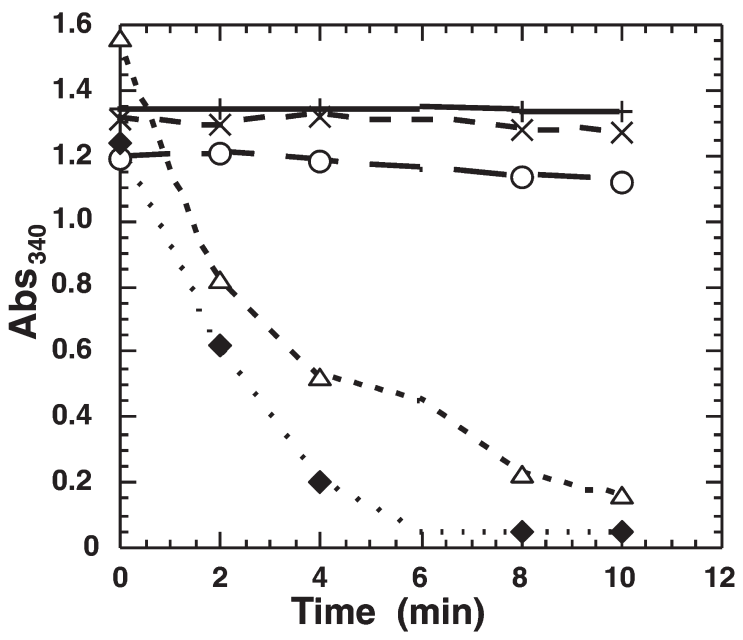

Figure 7. Cytoplasmic triosephosphate isomerase is present in spheroplasts. The activity of triosephosphate isomerase was measured with a coupled assay as described in Materials and methods. Oxidation of NADH was monitored over time with A. fulgidus whole- cell extract $(\diamond)$, sonicated protease-treated cells $(\triangle)$, reaction mix (with whole-cell extract) minus glycerol-3-phosphate dehydrogenase $(\bigcirc)$, reaction mix minus glyceraldehyde-3-phosphate $(x)$ and NADH in reaction buffer $(+)$.

A. fulgidus cells with those in protease-treated cells. When whole cells were assayed for NADH oxidase activity, several bands appeared, indicating the presence of multiple proteins with NADH oxidase activity. When protease-treated cells were assayed in parallel, most of the oxidase activity was absent (Figure 9). Although this assay does not distinguish be-

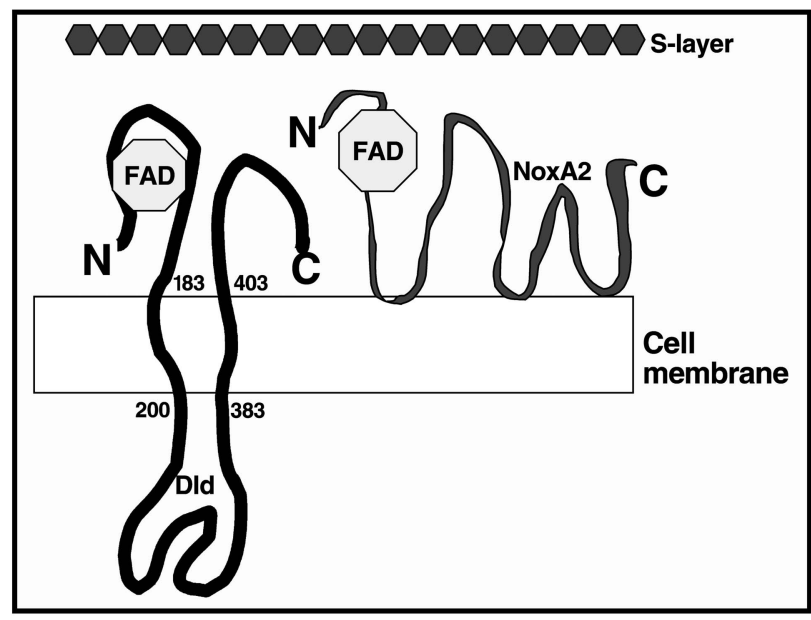

Figure 8. Proposed topology for Dld and NoxA2. Based on the $\beta \alpha \beta$ fingerprint, the predicted binding motif for the ADP portion of FAD is present between residues 68 and 95 in Dld. The regions between residues 183-200 and 383-403 are potential transmembrane regions. There are two candidate binding motifs between the amino acid residues 2-32 and 144-175 for ADP in NoxA2, which binds both FAD and NADH. Short hydrophobic regions between residues 148-153, 230-234, 396-397 of NoxA2 are potential sites of contact with the membrane. 
tween soluble oxidases that are in the periplasm versus the cell surface, we can conclude that the plethora of enzymes with oxidase activity in A. fulgidus reside outside the cytoplasm. Several of the A. fulgidus Nox enzymes, including NoxA1, NoxA2, NoxA3 and NoxA5, have a cysteine residue at or near Position 42 that may form a stable cysteine-sulfenic acid, first described in Enterococcus faecalis (Ahmed and Claiborne 1989 ), which can act in concert with FAD to carry out the $4 e^{-}$ reduction of $\mathrm{O}_{2}$ to $\mathrm{H}_{2} \mathrm{O}$.

\section{Discussion}

Substrates such as sodium lactate serve as electron donors for the dissimilatory sulfate reduction pathway. Archaeoglobus fulgidus has two lactate dehydrogenases that catalyze the oxidation of lactate to pyruvate: D-lactate dehydrogenase (Dld; specific for D-lactate) and L-lactate dehydrogenase (Lld; specific for L-lactate). To fulfill their role in anaerobic respiration, each enzyme is expected to be associated with the membrane, which has been confirmed experimentally. Many questions remain about the precise orientation of these enzymes in the membrane and the proteins that they interact with during electron transfer.

Using algorithms trained on bacterial proteins, the $50 \mathrm{kDa}$ Dld is predicted to be an integral membrane protein. Our immunocytochemical studies confirm that Dld is located near the membrane, and analysis of the size of Dld remaining in cells treated with protease showed that Dld is integrated into the membrane. Results from protease digestion indicate that roughly half of the protein (about $26 \mathrm{kDa}$ ) is sensitive to degradation, presumably because portions of Dld are exposed to the periplasmic side of the membrane. This corresponds precisely with predictions that the $183 \mathrm{~N}$-terminal amino acids and the 60 C-terminal amino acids of Dld are periplasmic. If Dld inserted into the membrane in the opposite orientation $(\mathrm{N}$ - and C-termini inside), we would have expected to see two bands at

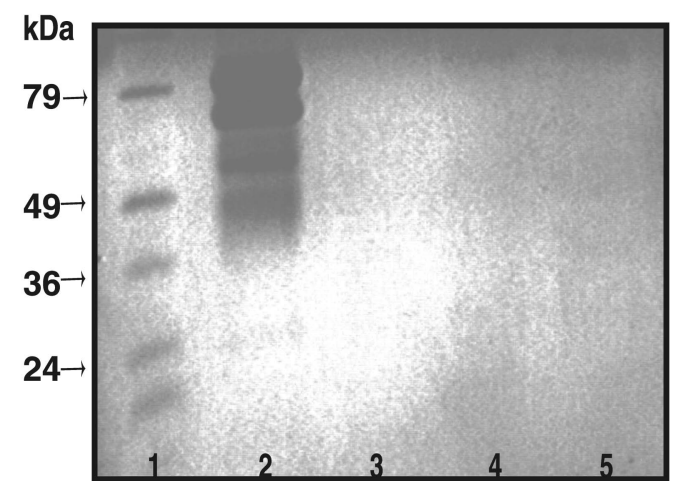

Figure 9. The activity of multiple NADH oxidases is abolished by treatment with protease. Whole cells of A. fulgidus were separated by SDS-PAGE, renatured and assayed for NADH oxidase activity as described in Materials and methods. Lane 1: prestained protein standards; Lane 2: untreated whole cells; Lane 3: whole cells treated with protease for $10 \mathrm{~min}$; Lane 4: whole cells treated with protease for $20 \mathrm{~min}$; Lane 5: whole cells treated with protease for $30 \mathrm{~min}$.
6.7 and $21 \mathrm{kDa}$. Previously we have found both soluble and membrane-associated Dld in cell extracts and it was thought that the soluble Dld was a cytoplasmic form destined for the membrane. Hence, it was surprising that some intact (cytoplasmic) Dld, which would have been protected from protease, was not detected. This apparent inconsistency was found to be a result of the formation of micelles containing Dld during lysis, which fail to sediment with the membrane fraction upon centrifugation.

Previously we have shown that Dld binds FAD in a 1:1 stoichiometry. If we are correct in predicting the topology for Dld, this places the invariant glycines that bind ADP and the glutamate that forms a hydrogen bond with the $2^{\prime}$ hydroxyl group of the adenosine ribose in the s-periplasm. A model of the topology of Dld as an integral membrane protein is shown in Figure 8.

The NoxA2 protein is an NADH oxidase that remains associated with Dld during purification of Dld from A. fulgidus. Consistent with this, we found that NoxA2, like Dld, is associated with the membrane in thin sections of A. fulgidus cells and that over $80 \%$ of the NoxA 2 protein is clustered with Dld. Virtually all of the NoxA2 protein is located in the s-periplasmic space. Taken together, these data show that NoxA2 and Dld either interact directly with one another in vivo or that each is part of the same protein complex. The finding that a significant portion of the NoxA2 activity is associated with the membrane in crude extracts reinforces the notion that NoxA2 interacts with an integral membrane protein.

Secreted and membrane proteins usually have a cleavable $\mathrm{N}$-terminal signal sequence for their targeting to respective sites. Therefore, it is puzzling that neither Dld nor NoxA2 has a signal sequence that is recognized by programs trained on either gram-positive bacteria, gram-negative bacteria or eukaryotes. Furthermore, the N-terminal sequence for Dld and NoxA2 isolated from A. fulgidus agrees with the predicted $\mathrm{N}$-terminus, indicating that neither protein is processed. Both Dld and NoxA2 require a bound FAD moiety for enzymatic activity, which is probably bound to Dld and NoxA2 in the cytoplasm before the proteins are directed to their final destination. In bacteria and eukaryotes, a subset of proteins containing a bound cofactor are exported by the twin arginine translocase (Tat) system (Weiner et al. 1998). The presence of a TatC homolog has been predicted for A. fulgidus (Eichler 2000). The A. fulgidus gene AF1512 is predicted to encode a protein that has $29 \%$ identity and $48 \%$ similarity over 259 amino acids with TatC, an essential member of the Tat protein complex. The primary amino acid sequences of both proteins have been examined for the presence of a tat motif (S/T-RR-X-F-L-K), but none has been detected. Archaeoglobus fulgidus might use a unique system to export cofactor-bound proteins or its Tat homolog may recognize a different motif.

The NoxA2 protein is one of at least eight NADH oxidases produced in A. fulgidus that range in size from about 20 to $70 \mathrm{kDa}$. Some NADH oxidases are thought to be involved in protecting anaerobes from $\mathrm{O}_{2}$ toxicity by reducing oxygen to $\mathrm{H}_{2} \mathrm{O}_{2}$ or $\mathrm{H}_{2} \mathrm{O}$. Archaeoglobus fulgidus conforms to this idea because it is not killed by exposure to $\mathrm{O}_{2}$ (P.L. Hartzell and 
D. DeGroot, University of Idaho, unpublished data). In contrast, close relatives such as Methanococcus jannaschii, Methanobacterium thermoautotrophicum $\Delta \mathrm{H}$ and Methanosarcina barkeri, which are typically killed on exposure to $\mathrm{O}_{2}$ (Balch et al. 1979, Rothe and Thomm 2000), have only one, three and three Nox enzymes, respectively. Alternatively, the presence of so many NADH oxidases may be characteristic of dissimilatory sulfate or sulfite reducers because, like A. fulgidus, the genome of Desulfitobacterium hafniense encodes seven or more NADH oxidases. A search against the incomplete Desulfovibrio vulgaris genome for homologs of NoxA2 identifies at least six open reading frames that encode proteins that share more than $34 \%$ identity with NoxA2 over at least 200 residues.

Our results show that the majority of the Nox enzymes in A. fulgidus are expressed during growth on D-lactate under strictly anaerobic conditions. Hence, it appears that these enzymes are expressed constitutively. If Nox proteins are a first line of defense against $\mathrm{O}_{2}$, it would make sense to locate them near the surface of the cell. Accordingly, we find that the activity of each Nox enzyme is destroyed in cells that have been treated with protease, which shows that each Nox enzyme is either a soluble periplasmic protein like NoxA2 or a membrane protein with domains critical for activity located in the periplasm.

D-Lactate dehydrogenase can routinely be manipulated in an aerobic environment without a significant loss of activity (Reed and Hartzell 1999). If NoxA2 is needed only to maintain a reduced environment, other oxidases should be able to satisfy this need. Yet despite the presence of many Nox proteins in the periplasm, only NoxA2 associates with Dld. This specific interaction and the close association between NoxA2 and Dld insinuates that NoxA2 may play more than just a protective role.

We have found that purified NoxA2 is a diaphorase because it can reduce commercially available $c$-type cytochromes (Reed et al. 2001). Hence, in vivo NoxA2 may donate electrons to other carriers, such as the periplasmic cytochrome $\mathrm{c}$ of A. fulgidus. The NADH oxidase from $D$. vulgaris has been shown to reduce adenylyl phosphosulfate reductase (Chen et al. 1994). The NADH oxidase from Acidianus ambivalens has been shown to donate electrons to a (3Fe-4S) ferredoxin center (Gomes and Teixeira 1998). The NoxA2 is also a potential donor for neelaredoxin, a small blue-colored protein in A. fulgidus that can reduce superoxide $\left(\mathrm{O}_{2}{ }^{-}\right)$. Neelaredoxin can dismutate $\mathrm{O}_{2}{ }^{-}$to $\mathrm{O}_{2}$ and $\mathrm{H}_{2} \mathrm{O}_{2}$, or directly reduce $\mathrm{O}_{2}$ to $\mathrm{H}_{2} \mathrm{O}_{2}$. In the latter reaction, an oxidized form of neelaredoxin is generated and subsequent reduction of neelaredoxin has been shown to require an NADH oxidase (Abreu et al. 2000). Hence NoxA2 may play a role in regenerating active neelaredoxin. Work is underway to identify other proteins that interact with NoxA2 in vivo.

\section{Acknowledgments}

We thank the faculty and staff of the electron microscopy center at Washington State University for advice and training. This work was supported by Grant MCB9906433 from the National Science Foundation to P.L.H.

\section{References}

Abreu, I.A., L.M. Saraiva, J. Carita, H. Huber, K.O. Stetter, D. Cabelli and M. Teixeira. 2000. Oxygen detoxification in the strict anaerobic archaeon Archaeoglobus fulgidus: superoxide scavenging by neelaredoxin. Mol. Microbiol. 38:322-334.

Abreu, I.A., L.M. Saraiva, C.M. Soares, M. Teixeira and D.E. Cabelli. 2001. The mechanism of superoxide scavenging by Archaeoglobus fulgidus neelaredoxin. J. Biol. Chem. 276: 38,995-39,001.

Ahmed, S.A. and A. Claiborne. 1989. The streptococcal flavoprotein NADH oxidase. 1. Evidence linking NADH oxidase and NADH peroxidase cysteinyl redox centers. J. Biol. Chem. 264: 19,856-19,863.

Altschul, S., F.W. Gish, W. Miller, E.W. Myers and D.J. Lipman. 1990. Basic local alignment search tool. J. Mol. Biol. 215: 403-410.

Balch, W.E., G.E. Fox, L.J. Magrum, C.R. Woese and R.S. Wolfe. 1979. Methanogens: Reevaluation of a unique biological group. Microbiol. Rev. 43:260-296.

Berridge, M.V. and A.S. Tan. 2000a. Cell-surface NAD(P)H-oxidase: relationship to trans-plasma membrane NADH-oxidoreductase and a potential source of circulating NADH-oxidase. Antioxid. Redox Signal 2:277-288.

Berridge, M.V. and A.S. Tan. 2000b. High capacity redox control at the plasma membrane of mammalian cells: trans-membrane, cell surface, and serum NADH-oxidases. Antioxid. Redox Signal 2: 231-242.

Berryman, M.A. and R.D. Rodewald. 1990. An enhanced method for post-embedding immunocytochemical staining which preserves cell membranes. J. Histochem. Cytochem. 38:159-170.

Brockman, H.J., Jr. and W.A. Wood. 1975. D-Lactate dehydrogenase of Peptostreptococcus elsdenii. Methods Enzymol. 41:309-312.

Broome-Smith, J., K.S. Gnaneshan, L.A. Hunt, F. Mehraein-Ghomi, L. Hashemzadeh-Bonehi, M. Tadayyon and E.S. Hennessey. 1994. Cleavable peptides are rarely found in bacterial cytoplasmic membrane proteins. Mol. Membr. Biol. 11:3-8.

Brown, D.M., J.A. Upcroft, M.R. Edwards and P. Upcroft. 1998. Anaerobic bacterial metabolism in the ancient eukaryote Giardia duodenalis. Int. J. Parasitol. 28:149-164.

Chen, L., J. Le Gall and A.V. Xavier. 1994. Purification, characterization, and properties of a NADH oxidase from Desulfovibrio vulgaris (Hildenborough) and its coupling to adenylyl phosphosulfate reductase. Biochem. Biophys. Res. Comm. 203:839-844.

Cserzo, M., E. Wallin, I. Simon, G. von Heijne and A. Elofsson. 1997. Prediction of transmembrane alpha-helices in procaryotic membrane proteins: The dense alignment surface method. Prot. Eng. 10:673-676.

Dahl, C., H. Koch, O. Keuken and H.G. Truper. 1990. Purification and characterization of ATP sulfurylase from the extremely thermophilic archaebacterial sulfate-reducer, Archaeoglobus fulgidus. FEMS Microbial. Lett. 67:27-32.

Eichler, J. 2000. Crossing membranes in the third domain of life. Eur. J. Biochem. 267:3402-3412.

Gomes, C.M. and M. Teixeira. 1998. The NADH oxidase from the thermoacidophilic archaea Acidianus ambivalens: Isolation and physicochemical characterisation. Biochem. Biophys. Res. Comm. 243:412-415.

Hansen, T.A. 1988. Physiology of sulfate-reducing bacteria. Microbiol. Sci. 5:81-84.

Hansen, T.A. 1994. Metabolism of sulfate-reducing prokaryotes. Antonie Leeuwenhoek 66:165-185.

Hofmann, K. and W. Stoffel. 1993. TM base: A database of membrane spanning protein segments. Biol. Chem. Hoppe-Seyler 47: 166. 
Itoh, T., K. Suzuki, P.C. Sanchez and T. Nakase. 1999. Caldivirga maquilingensis gen. nov., sp. nov., a new genus of rod-shaped crenarchaeote isolated from a hot spring in the Philippines. Int. J. Syst. Bacteriol. 49:1157-1163.

Krogh, A., B. Larson, G. von Heijne and E.L.L. Sonnhammer. 2001. Predicting transmembrane protein topology with hidden Markov model: Application to complete genomes. J. Mol. Biol. 305: 567-580.

Mallett, T.C. and A. Claiborne. 1998. Oxygen reactivity of an NADH oxidase $\mathrm{C} 42 \mathrm{~S}$ mutant: Evidence for a $\mathrm{C}(4 \mathrm{a})$-peroxyflavin intermediate and a rate-limiting conformational change. Biochem 37: 8790-8802.

Ne' eman, Z. and S. Razin. 1975. Characterization of the mycoplasma membrane proteins. Release and localization of membrane-bound enzymes in Acheoplasma laidlawii. Biochim. Biophys. Acta 375: $54-68$.

Nishiyama, Y., V. Massey, K. Takeda, S. Kawasaki, J. Sato, T. Watanabe and Y. Niimura. 2001. Hydrogen peroxide-forming NADH oxidase belonging to the peroxiredoxin oxidoreductase family: Existence and physiological role in bacteria. J. Bacteriol. 183: 2431-2438.

Reed, D.W. and P.L. Hartzell. 1999. The Archaeoglobus fulgidus D-lactate dehydrogenase is a $\mathrm{Zn}^{2+}$ flavoprotein. J. Bacteriol. 181: 7580-7587.

Reed, D.W., J. Millstein and P.L. Hartzell. 2001. $\mathrm{H}_{2} \mathrm{O}_{2}$-forming $\mathrm{NADH}$ oxidase with diaphorase (cytochrome) activity from Archaeoglobus fulgidus. J. Bacteriol. 183:7007-7016.

Reno, W.M. 2001. Post-embedding double-gold labeling immunoelectron microscopic co-localization of neurotransmitters in the rat brain. Med. Sci. Monit. 7:188-200.

Ross, R.P. and A. Claiborne. 1992. Molecular cloning and analysis of the gene encoding the NADH oxidase from Streptococcus faecalis 10C1. Comparison with NADH peroxidase and the flavoprotein disulfide reductases. J. Mol. Biol. 227:658-671.
Rothe, O. and M. Thomm. 2000. A simplified method for cultivation of anaerobic Archaea based on the use of sodium sulfite as a reducing agent. Extremophiles 4:247-252.

Schagge, H. and G. von Jagow. 1987. Tricine-sodium dodecyl sulfate-polyacrylamide gel electrophoresis for the separation of proteins in the range from 1 to $100 \mathrm{kDa}$. Anal. Biochem. 166: 386-379.

Speich, N., C. Dahl, P. Heisig, A. Klein, L. Friedrich, K.O. Stetter and H.G. Truper. 1988. Adenylsulfate reductase from the sulfate reducing archaeon Archaeoglobus fulgidus: cloning and characterization of the genes and comparison of the enzyme with other iron-sulfur flavoproteins. Microbiology 140:1273-1284.

Stetter, K.O. 1988. Archaeoglobus fulgidus gen. nov., sp. nov.: a new taxon of extremely thermophilic Archaebacteria. System. Appl. Microbiol. 10:172-173.

Stetter, K.O. 1992. The genus Archaeoglobus. In The Prokaryotes. Eds. A. Balows, H.G. Trüper, M. Dworkin, W. Harder and K.H. Schleifer. Springer-Verlag, New York, pp 707-711.

Terzakis, J.A. 1968. Uranyl acetate: a stain and a fixative. J. Ultrastruct. Res. 22:166-184.

von Heijne, G. 1988. Transcending the impenetrable: How proteins come to terms with membranes. Biochem. Biophys. Acta 947: 307-333.

von Heijne, G. 1992. Membrane protein prediction, hydrophobicity analysis and the positive-inside rule. J. Mol. Biol. 225:487-494.

Ward, D.E., C.J. Donnelly, M.E. Mullendore, J. van der Oost, W.M. de Vos and E.J. Crane. 2001. The NADH oxidase from Pyrococcus furiosus. Implications for the protection of anaerobic hyperthermophiles against oxidative stress. Eur. J. Biochem. 268:5816-5823.

Weiner, J.H., P.T. Bilous, G.M. Shaw, S.P. Lubitz, L. Frost, G.H. Thomas, J.A. Cole and R.J. Turner. 1998. A novel and ubiquitous system for membrane targeting and secretion of cofactor-containing proteins. Cell 93:93-101. 

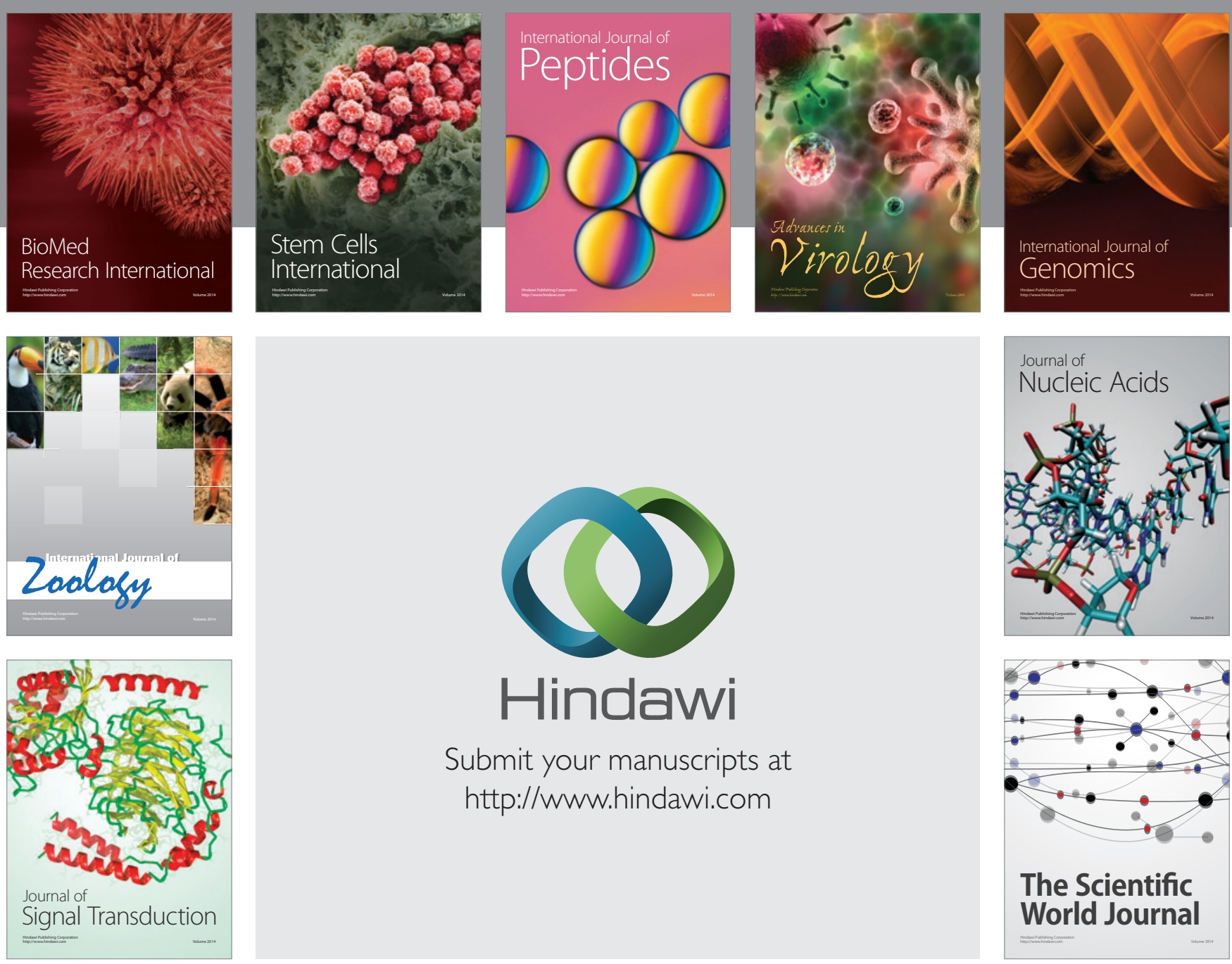

Submit your manuscripts at

http://www.hindawi.com
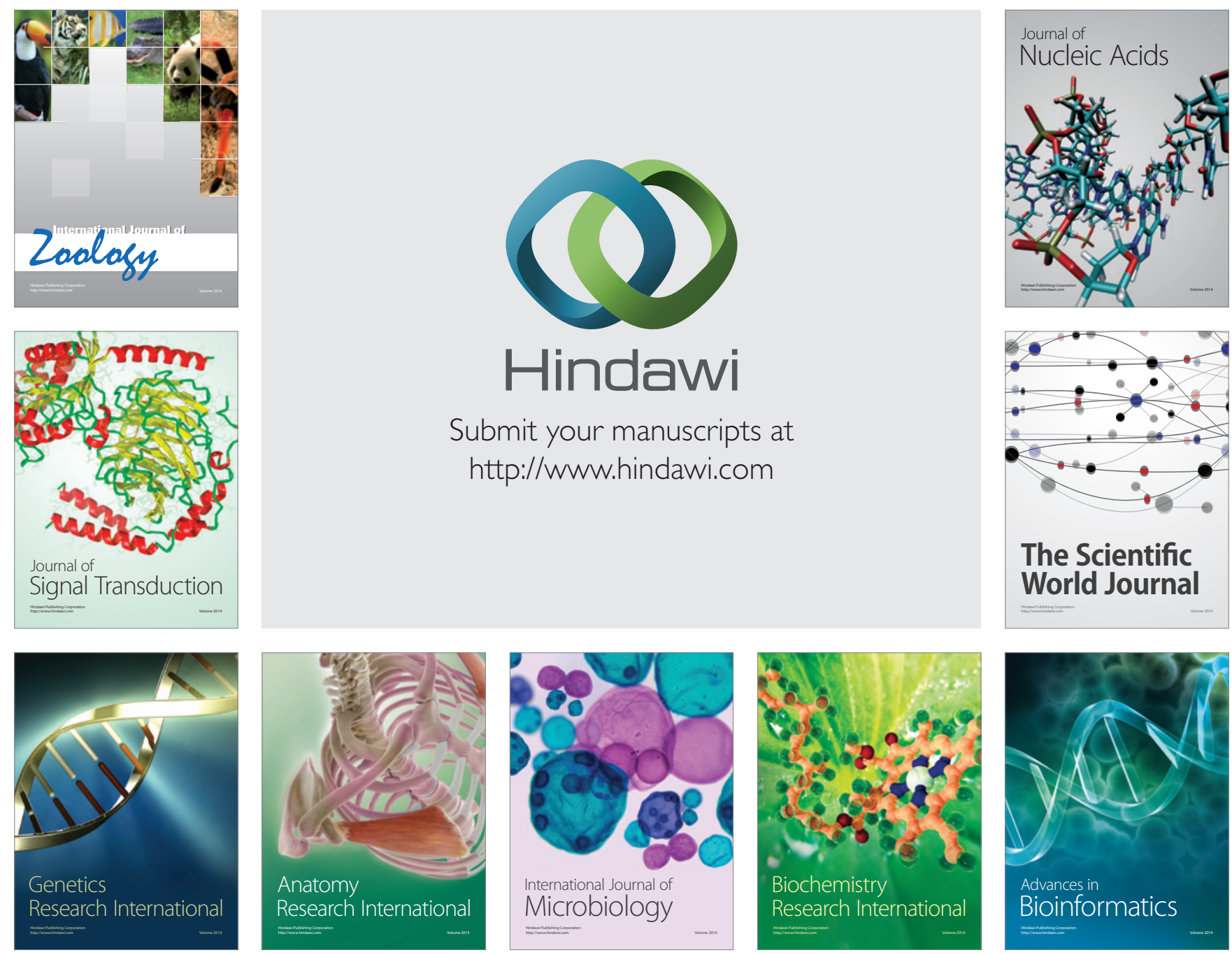

The Scientific World Journal
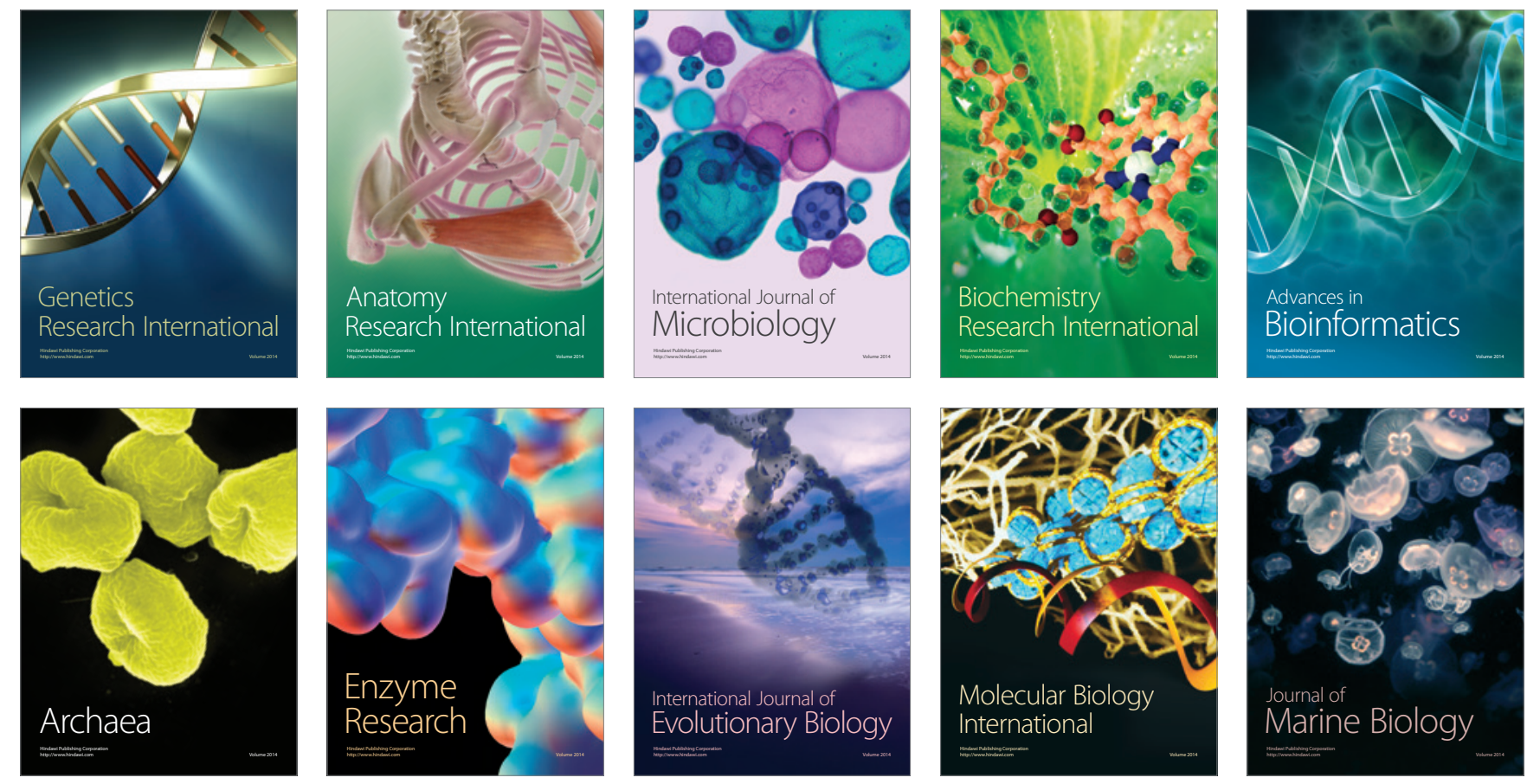